\title{
Temporal avoidance conditioning in the cat ${ }^{1,2}$
}

DAVID C. STEINBRECHER AND RUSSELL A. LOCKHART

UNIVERSITY OF CALIFORNIA, SANTA BARBARA

Cats were trained in a temporal avoidance conditioning paradigm in which a regularly occurring shock could be avoided only by jumping a barrier within $15 \mathrm{sec}$. prior to shock onset. Seventy-five percent of the animals exhibited significant temporal avoidance within 200 trials compared with $43 \%$ in an earlier study involving rabbit Ss. No difference was found between species when Ss showing significant temporal avoidance were compared.

Sidman (1962, 1966) has described a number of procedures for establishing avoidance behavior in situations without an extroceptive warning stimulus. In one of these procedures (limited interval avoidance) the training session (following a fixed-cycle shaping period) is divided into successive $15 \mathrm{sec}$. cycles which cannot be modified by S's behavior. A shock scheduled to occur at the end of each cycle can be avoided only if a response (bar-press) is made within some predetermined time interval during the cycle (e.g., within 3 sec. prior to shock onset). A similar procedure (without shaping) has been used by Lockhart \& Steinbrecher (1965) to determine if this quasi-classical conditioning approach could be utilized in temporally conditioning a shuttle-box avoidance response. Rabbit Ss were placed in a double grid-box and given a shock every 50 sec. The current remained on until $S$ escaped by jumping a barrier. Shock could be avoided only if a jump occurred within the last $15 \mathrm{sec}$. of the interval. Temporal avoidance conditioning was observed but the phenomenon was difficult to develop and subject to wide individual differences. On the assumption that the difficulty of conditioning such a response would be related to phyletic level, cats were trained under the same paradigm as were the rabbits.

Method

The Ss were three male and five female cats, ranging in age from 6 to 18 months. All animals were trained in a $5 \times 2 \times 2-f t$. two compartment shuttle-box with an 8-in. barrier in the center. Either side of the grid floor could be charged with up to a 40 ma current provided by a Grayson-Stadler shock generator (Model E6070B). The shuttle-box was located in a sound attenuated room with a background illumination provided by twelve 12-w fluorescent lights. Under these conditions there were no apparent external cues available to the animals. Ss were viewed through a one-way mirror and $\mathrm{E}$ recorded the number and latency of all barrier crossings.

$S$ was placed in the shuttle-box and received shock at $60 \mathrm{sec}$. intervals. The current remained on until $\mathrm{S}$ escaped by jumping the barrier. After initial shocks, jump latency averaged about $1 \mathrm{sec}$. Each $60 \mathrm{sec}$. time
Table 1. Mean number of jumps per session in avoidance and control intervals for each $\mathrm{S}$.

S

\begin{tabular}{lccc}
$S$ & Avoidance & $\begin{array}{c}\text { Mean Number of Jumps } \\
\text { Control }\end{array}$ & Difference \\
\hline 1 & 5.04 & 2.72 & $2.32^{* *}$ \\
2 & 3.23 & 1.30 & $1.93^{* *}$ \\
3 & 1.20 & .65 & .55 \\
4 & 2.75 & 1.15 & $1.60^{* *}$ \\
5 & 5.24 & 3.40 & $1.84^{* *}$ \\
6 & 4.10 & 2.65 & $1.45^{*}$ \\
7 & .30 & .25 & .05 \\
8 & 2.70 & 1.85 & $.85^{*}$ \\
\hline
\end{tabular}

$* p<.05, * * p<.0005$

interval was considered as one trial independently of S's behavior. Shock could be avoided only if the cat jumped within a 15 sec.periodijust prior to shock onset.

For each training session the number of jumps occurring during a 15 sec. "control" interval prior to the avoidance interval was subtracted from the number of avoidance responses to yield a temporal avoidance score.

All animals received 10 trials per training session. The number of sessions per $S$ was as follows: $S 1=30$, Ss $2,5=25$, and Ss $3,4,6,7,8=20$.

\section{Results}

Table 1 presents the mean number of jumps in avoidance and control intervals over all trials for each S. Table 2 presents the mean percent of temporal avoidance (defined as the difference in percent between the avoidance and control intervals) for each cat for each fifth of acquisition.

Overall comparison (Wilcoxon matched-pairs signed ranks test) of avoidance and control responses indicated that six of the eight Ss jumped significantly more during the period leading to shock avoidance than during a period in which responses had no instrumental consequence. Similar significant differences were found in five of seven rabbit Ss. However, the latter comparisons were based on several hundred trials.

Table 2. Mean \% Temporal Avoidance for each Fifth of Acquisition for each $\mathrm{S}$ over all Trials.

\begin{tabular}{|c|c|c|c|c|c|c|}
\hline \multirow{2}{*}{$\mathbf{S}$} & \multicolumn{5}{|c|}{ Blocks of Trials } & \multirow{2}{*}{$\begin{array}{r}\bar{X} \% \text { Temporo } \\
\text { Avoidance }\end{array}$} \\
\hline & 1 & 2 & 3 & 4 & 5 & \\
\hline 1 & 10.00 & 36.00 & 34.00 & 18.00 & 20.00 & 29.00 \\
\hline 2 & 0.00 & 3.33 & 8.33 & 40.00 & 47.00 & 19.72 \\
\hline 3 & 5.00 & 5.00 & 2.50 & 7.50 & 12.50 & 6.50 \\
\hline 4 & 0.00 & 2.50 & 17.50 & 15.00 & 45.00 & 16.00 \\
\hline 5 & 4.00 & 2.00 & 36.00 & 26.00 & 24.00 & 18.40 \\
\hline 6 & -2.50 & 15.00 & 0.00 & 12.00 & 52.00 & 15.30 \\
\hline 7 & 0.00 & 2.50 & 2.50 & 0.00 & 2.50 & 0.50 \\
\hline 8 & -2.50 & -2.50 & 22.50 & 10.00 & 15.00 & 8.50 \\
\hline $\bar{x}$ & 1.75 & 7.98 & 11.58 & 16.06 & 26.60 & \\
\hline
\end{tabular}




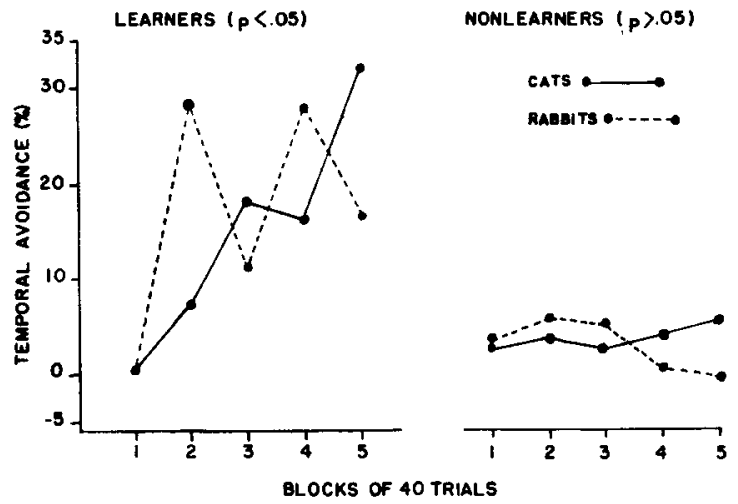

Fig. 1. Mean temporal avoidance $(\%)$ for each block of 40 trials for cat and rabbit learners and non-learners.

To facilitate a more direct comparison between cat and rabbit Ss the mean percent temporal avoidance during the first 200 trials was employed. Under these conditions it was found that only three rabbits (Ss 1, $10,13)$ exhibited significant $(p<.05)$ performance while six cat $\operatorname{Ss}(1,2,4,5,6,8)$ did so. Figure 1 shows the acquisition data for "learners" and "non-learners" in each species.

\section{Discussion}

The assumption that success in a temporal avoidance task is related to phyletic level receives support from the present comparisons. A greater percentage of cats than rabbits learned the problem to a criterion of within-subject significance. The phyletic variable, however, was found to be related only to the proportion of animals conditioning and not to the degree of conditioning. No difference was found between species when animals exhibiting significant temporal avoidance were compared.

It should be noted that both rabbits and cats develop one of three characteristic response patterns to the avoidance situation. Rabbits 1 and 13 and cats 2 and 4 developed a fairly high rate of avoidance responding with little responding during the non-critical portion of the intertrial interval. Rabbits 8 and 12 and cats
1, 5 and 6 avoided the shock more frequently than all other Ss, but also developed a "jumping syndrome," i.e., they would jump the barrier a large number of times throughout each $60 \mathrm{sec}$. interval. All other Ss were characterized by relatively little responding and therefore received the largest number of shocks.

We should also note, as has Sidman (1966), that there is no necessary relation between the formation of a temporal discrimination and successful avoidance. There are three important points to be made in this regard: (1) animals receiving the most shocks-and therefore with the most opportunity to form temporal discriminations-develop little tendency to avoid shock; (2) animals receiving the least number of shocks seem to develop a jumping syndrome in which there is little (yet significant) temporal discrimination; and (3) animals developing the highest degree of temporal avoidance discrimination receive more shocks than those animals developing the jumping syndrome, indicating that the phenomenon is imprecise and irregular. Whether these three response patterns are the result of some fortuitous reinforcement contingencies or to individual differences we cannot say. It is evidence that the relationship between temporal discrimination and shock avoidance in a shuttle-box situation lacking extroceptive warning stimuli is quite complex. Explorations of this relationship are presently under way.

\section{References}

Lockhart, R. A., \& Steinbrecher, D. C. Temporal avoidance conditioning in the rabbit. Psychon. Sci., 1965, 3, 121-122.

Sidman, M. Classical avoidance without a warning stimulus. $J$. exp. Anal. Behav., 1962, 5, 97-104.

Sidman, M. Avoidance behavior. In W. K. Honig (Ed.), Operant behavior: areas of research und application. New York: Appleton-Century-Crofts, 1966.

\section{Notes}

1. This investigation was supported by grants to the second author from the Public Health Service (Grant MH 11723-01) and the Faculty Research Committee, University of California, Santa Barbara.

2. The authors are indebted to Mary Kidd, David Darnell and John Shea for their assistance in the data collection. 